\title{
REVIEW OF DIFFERENT ANTHROPOMETRIC AND NUTRITIONAL MEASUREMENTS IN CHILDREN WITH BRONCHIAL ASTHMA
}

\author{
Gundega Lipsberga, Dzintra Kažoka \\ Institute of Anatomy and Anthropology, Riga Stradinš University \\ Riga, Latvia
}

\begin{abstract}
The aims of this study were to describe and compare the recent literature data of anthropometric and nutritional measurements in children with bronchial asthma from the researches published in the last 10 years. 46 studies from the year 2003 to 2014 were reviewed and analyzed along with the information published before. The measurements reviewed include body height, body weight, body mass index and body composition.

The severity and duration of bronchial asthma, along with the inhaled corticosteroid treatment, negatively correlate with the height of the children. Also, the fat free mass of the body is decreased and fat mass is increased. Due to more robust body build and the body mass index in children with bronchial asthma is usually increased if compared to healthy children. An increased body mass index in these children reduces the effectiveness of the treatment. Increased body mass index can also be a predictor for the risk for developing late onset bronchial asthma in girls.
\end{abstract}

Keywords: bronchial asthma, body mass index, body height, body weight, body composition, inhaled corticosteroids

\section{INTRODUCTION}

Bronchial asthma (BA) is a chronic lung disease, affecting up to $11 \%$ of the world population [25]. In Latvia it affects $2-5 \%$ of population (according to Latvia Alergologists Association data, 2010). The prevalence of BA in children in Latvia is $9.5 \%$, and $35 \%$ of the children affected by the disease is under the 
age of 2 years (according to Children Clinical University Hospital data, Riga, 2010).

According to different studies from the 1970s to the 1990s, bronchial asthma is one of the factors impacting the growth and development of children. Although a considerable number of studies, using different study designs, indicate that the risk of asthma development, the topic remains controversial because of potential methodological limitations inherent in many of these studies.

The aim of the study was to collect and analyze the recent literature data of anthropometric and nutritional measurements in children with bronchial asthma from the researches published from theb year 2003 to 2014 .

\section{MATERIAL AND METHODS}

Published papers were searched using the Medline/Pubmed database. Furthermore, references in the selected publications were checked for relevant publications not included in the Medline/Pubmed search.

\section{RESULTS}

Bronchial asthma, body height and body weight. It has been established since the 1980s that the children with BA tend to be lower in height than healthy children [35]. In the study carried out by Umlawska et al., 2013, which included 261 children with bronchial asthma, it was concluded that about 5\% of the children with BA were very short in stature: their height was under the 5 th percentile of the growth charts [48].

The height of the child with BA is impacted by several factors: the age at diagnosis, duration and the severity of the disease, recurrent respiratory infections, chest deformity, muscle shortening and postural adaptations, hypoxemia, the impaired pulmonary function, enhanced metabolic demands of the increased work of breathing and allergic processes and corticosteroid treatment $[19,26,48]$.

It has also been observed that the children with untreated or poorly treated asthma experience late onset puberty and the delay in pubertal growth spurt by approximately 1.3 years $[13,19]$.

The relative weight of the children with BA, however, may not be influenced by the disease. In the mentioned study carried out by Umlawska et al., 2013, there was no significant correlation between the severity or duration of the disease and relative body weight. However, the children with BA have a differ- 
ent body composition, compared to their healthy peers [48] (see the section "Bronchial asthma and body composition").

Bronchial asthma and the body mass index. The body mass index (BMI) is a nutritional measurement, defined as the individual's body mass divided by the square of their height - with the value in units of $\mathrm{kg} / \mathrm{m}^{2}$ [4]. In children, the BMI number is plotted on the BMI-for-age growth charts for girls or boys to obtain a percentile ranking. The BMI below the 5th percentile means underweight; the BMI between the 5th up to the 85th percentile means normal weight; the BMI between the 85th and the 95th percentile means overweight, and BMI above the 95th percentile means obesity [5].

It has been established since the 1980s that BA, as a chronic disease, has an impact on the BMI [32]. Still, there is no united opinion if BA can be responsible to increased or decreased BMI in both boys and girls.

A research carried out by Scepanovic et al., 2013, states that a significant number of children with BA are both overweight and underweight if compared for the healthy children. Considerable differences between the sick and healthy children occur in different age groups: boys differ at ages 8-9 and 13-15, whereas girls differ at ages 6-7 and 10-12 [41].

The results in different studies, however, show that the children with BA have an increased BMI, if compared to healthy children, and these differences can be found in all age groups. Ahmadiafshar et al., 2013, and Umlawska et al., 2013, state that there is no significant correlation between the BMI and the severity and treatment of the disease $[1,48]$. Another research by Szroniak et al., 2008, however, states that the severity of asthma correlates with the higher BMI [46].

The increased BMI in these children has an impact on the disease as well $[15,24,28]$. As stated in a research by Holguin et al, 2011, obese children with BA are more likely to have continuous cough, sputum production, chest tightness, wheeze, dyspnea, nocturnal symptoms, and a reduced quality of life if compared to the children with normal BMI or overweight. Similarly, they are more likely to have exacerbations, requiring oral steroids and the use of healthcare resources, including hospital visits, admissions in the Intensive care unit, and mechanical ventilation [24]. Obese and overweight children with BA tend to have reduced lung volume ratios (functional residual capacity/total lung capacity (TLC) and residual volume/TLC) [28]. Furthermore, the obese adolescents with BA have a higher prevalence of the metabolic syndrome than the obese adolescents without BA, more significantly in boys [11]. 
Bronchial asthma and body composition. The body composition is evaluated by distinguishing the fat mass (FM) and the fat free mass (FFM). Skinfold thickness measurements are widely used to assess the size of specific subcutaneous fat depots. Measuring waist circumference is a simple way to determine the central fatness [53]. Waist-to-height ratio can be used as a proxy measure of visceral adipose [40]. Body composition can be estimated using the upper arm muscle area (UMA), which can be calculated using the following formula: (arm circumference $-(\pi \times$ triceps skinfold thickness $))^{2} / 4 \pi$. The total upper arm area (TUA) can be calculated by the following formula: (upper arm circumference $)^{2} / 4 \pi$. The upper arm fat area then can be calculated using the formula: TUA-UMA [17].

The body fat percentage might be calculated, using the biolelectrical impedance [6] or estimated from BMI, using the following formula: $(1.51 \times \mathrm{BMI})-$ $(0.70 \times$ age $)-(3.6 \times$ sex $)+1.4$, where sex is 1 for boys and 0 for girls [12]

In a research of Antonio et al., 2003, it was concluded that the triceps skinfold in the girls with BA was significantly larger than in healthy girls [3]. As shown later in a study by Umlawska et al., 2013, between the children with BA, the upper arm circumference, the body fat content and the muscle mass were significantly higher in girls than boys; therefore, the body build was more robust [48].

It was published in 2009 by Musaad et al. that central obesity, determined by the waist circumference, is correlated with BA, the severity of the disease and the lower lung function [31]. Later several researches published from 2011 to 2014 state that wheezing and BA correlate with a larger waist circumference and a smaller waist-to height ratio [33, 43, 49].

A detailed research by Guibas et al., 2013, states that the measurements correlating with bronchial asthma differ depending on the age groups [21]. In the children aged 2-5 years, BA positively correlated with the waist-to-hip circumference; biceps, triceps, subscapular and suprailiac skinfold thickness; and skinfold-derived percentage fat mass but not BMI or BMI-defined overweight and obesity. In the children aged 9-13 years, BA was positively associated with the waist circumference, the waist-to-height ratio, skinfold thickness, skinfold-derived percentage fat mass, the BMI, the BMI-defined overweight or obesity.

Yiallouros et al., 2013, researched the body fat percentage correlation with BA. It was concluded that the body fat percentage was significantly higher in the children with BA in the age of 7-8 years and 16-17 years, but not in the age groups in between [56]. 
Bronchial asthma treatment with inhaled corticosteroids and its impact on the anthropometric and nutritional measurements. The Global Initiative for Asthma - GINA 2010 guidelines places emphasis on the use of inhaled corticosteroids (ICS) for asthma because they have reduced asthma mortality and morbidity; they reduce asthma symptoms, improve the lung function and reduce the number of exacerbations. However, one of the side effects of the ICS is effecting the growth. As published already in the year 200 by Davis et al., the ICS inhibit mediators of the growth axis in children, like the secretion and the action of the growth hormone, the action of insulin-like growth factors, collagen synthesis and adrenal androgen production. The effects of ICS depend on the type of the drug, the dose, and the amount of drug that is absorbed [9]. A study by Sim et al., 2003, suggested that high-dose ICS can induce adrenal suppression in children with BA [45]. In 2004 Mohn et al., published a research, suggestng that also low dose ICS treatments are associated with the adrenal axis suppression [30].

Studies show that the children with BA, who receive long-term inhaled corticosteroid therapy, have height deficits 1-2 years after the treatment initiation that persist into adulthood [18]. The height deviation scores negatively correlate with the severity of asthma and a larger ICS dose [36, 39]. Also, younger, prepubertal children, appear more sensitive to the growth suppressive effects of ICS. It has also been established that using of the ICS also results in delayed puberty $[13,14]$.

The ICS treatment seems to influence the bone age of the short bones. A research by Wang et al., 2012, measured radius, ulna, carpal bones and short finger bones for the bone age of the children before and one year after an inhaled glucocorticosteroid treatment [52]. It was concluded that the treatment with ICS for one year may suppress the level of carpal bone age, but the level of radius, ulna and short finger bones ' bone age are not affected during one year of the ICS treatment [36]. However, the long-term treatment with inhaled corticosteroid therapy is safer than the frequent doses of oral corticosteroids, for its side effect on disrupting the normal bone mineralization [18].

The question, if the ICS treatment for BA in children makes them shorter adults, has been urgent. The latest results, published by Raissy et al., 2013, show growth retardation, not suppression, in adult heights of the children who were treated with ICS [37]. The effect of the ICS is sustained and not cumulative and can be reduced with the appropriate selection of ICS with the highest therapeutic index on the lowest effective dose. The reduction in the final adult height is unlikely to exceed $1.2 \mathrm{~cm}$ and the ICS effect on growth, is outweighed by the benefits of the ICS treatment $[13,37]$. 
The body composition and BMI might also be affected by the ICS treatment. The ICS may affect lipid metabolism and increase the adipose mass, as published already in 2001 by Aldamiz-Echevarria et al, whose research results showed that the boys with BA, who received ICS treatment for at least 12 months, had a lower fat free mass compared to those ICS free [2].

Several studies show that the BMI in children with BA, receiving ICS treatment, is generally higher than those who are ICS free [44, 50]. However, a study carried out by Wang et al., 2012, showed that during one year of ICS treatment in a medium dosage the BMI was not affected [52].

As the increased BMI has an influence on the disease, it also alters the therapeutic effects of the ICS. A research carried out by Ye Huang et al., 2013, evaluated the BMI and the lung function of the children with BA who received ICS treatment for one year [55]. It was concluded that the therapeutic effects of ICS are reduced in obese children.

Increased body mass index as a risk factor for bronchial asthma. In $2004 \mathrm{a}$ large study by To et al. was published including 11,199 Canadian children, who had an increased BMI and whose mothers had BA [47]. The results of this study showed that and the increased $\mathrm{BMI}$ is not a risk factor for developing $\mathrm{BA}$ in children.

But the latest studies show different results. Several researches among the populations of the USA, Puerto Rico, Australia and Canada, that include 60039000 children in several age groups, state that and the increased BMI (both overweight and obesity) is a risk factor for developing BA in girls. [7, 16, 20, $29,54]$.

Also the current research carried out by Hawlader et al., 2014, in Bangladesh, including 912 children, shows that also underweight and malnutrition constitute a risk factor for wheezing in both boys and girls [23].

There are few studies that prove the correlation between the increased BMI and the risk of BA in boys. A study by Porter et al., 2012, states that the boys with BMI above the 85 th percentile in the age of 8-9 years develop BA until the age of 18-20 years 7.4\% more times often, compared to the boys with BMI below the 85 th percentile at the age of $8-9$ years [34]. Similarly a research by Magnusson et al., 2012, states that both boys and girls with and increased BMI at the age of 4 years do not have an increased risk of developing BA, compared to the children with normal BMI [27]. However, an increased BMI at the age of 7 and more years correlates with an increased risk of developing BA for both sexes. 
Different researches in the past couple of years show that BMI alone is not enough to establish the risk of developing BA. A research by Wang $\mathrm{R}$ et al., 2013, analyzes not only the BMI, but also the percent body fat (PBF) and the percent truncal fat (PTF) [51]. It was revealed that increased PBF and PTF was associated with the reduced forced expiratory volume in the first second (FEV1) and forced vital capacity (FVC), but only in boys. In girls, the increased $\mathrm{PBF}$ and PTF correlated with the risk of developing BA. Another research by Chen et al., 2014, states that central obesity (increased abdominal circumference) is the most accurate predictor of the risk of developing BA in both boys and girls [8].

\section{DISCUSSION}

Two phenotypes of asthma are known in the overweight and obese: one group with the early onset BA, which is complicated by overweight or obesity, and another group with the late onset BA, which is consequent to obesity [42]. The majority of children with the early onset asthma are most likely to experience their first episode of BA until the age of 6 years. The late onset asthma, however, may be diagnosed variably from the age of 12 years to more than 65 years [10].

The children with the early onset asthma, as well as the children with the late onset asthma, diagnosed in early adulthood, will experience the changes in growth velocity and body composition. In the children with the late onset BA, however, the body composition and therefore BMI might already be altered and can be a significant risk factor for the disease to develop.

The children with the early onset BA are predisposed to a BMI increase, both overweight and obesity, due to the reduction in height and the increasing body fat amount and more robust body-build.

The inflammatory mediators that are responsible for the immune process of BA are cytokines, chemokines, growth factors, obesity related cytokines (or adipokines), immunoglobulins and histamine. Overweight and obesity lead to changes in immune cell function and changes in immunometabolism [22, 38]. This is a relatively new field of research, and future studies may give a better understanding of the mechanism of the increase of the body fat in the children with BA. Also, as stated in 1992 by Zeitlin et al., the basal metabolic rate is higher in the children with BA than in healthy children because of the increased difficulty in breathing [57].

The height, the BMI and the body composition in children with both the early and the late onset BA are affected by the disease mechanisms and the 
severity of the disease, as well as the ICS treatment. The growth delay can be observed in the children who have poor asthma control, as well as it can negatively correlate with the higher doses of the ICS received for treatment. The ICS effect on growth, however, is less significant compared to the benefits of the ICS treatment.

It is unclear whether higher BMI is associated with the duration and the severity of the disease. The ICS effect on the BMI and the body composition is also debatable. It is more likely for the ICS adverse effects to appear after a systematic use in a longer period of time and depend on the dosage and the type of the corticosteroid.

The height, weight and the BMI should be regularly controlled in the children with $\mathrm{BA}$; measuring of skinfold thickness, the waist circumference and the waist-to-height ratio may also be beneficial. The frequency of taking measures, however, is not determined. If a child's BMI is evaluated at least twice a year, it may benefit in the early determining of the risk of overweight and obesity, and perhaps a different diet or exercise regimen can be applied. Otherwise these children may become less responsive to the ICS treatment and will be predisposed to a more severe presentation of the BA due to overweight and obesity.

It is still unclear whether and which measurements are the most effective predictors for the risk of developing the late onset BA in both sexes. The measurements and the correlating risk factors depend on the sex and the age of the child. It has been established that increased BMI, both overweight and obesity, can be a predicting risk factor for developing BA in girls, most effectively from the age of 7 years. A decreased BMI in small children can be a risk factor of wheezing. More studies are necessary for establishing the significance in PBF and PTF as well as the central obesity in predicting the risk of BA in boys and girls.

\section{CONCLUSIONS}

This information, which has been generated by different studies, offers a possibility for comparing the impact of BA on the anthropometric and nutritional development of children. The severity and duration of BA, along with the ICS treatment, negatively correlate with the height of the children. The relative body weight may not be influenced by bronchial asthma; however, the FFM is decreased and the FM is increased. The BMI in children with BA, compared to healthy children, can be increased due to a more robust body build. An increased BMI in the children with BA reduces the effectiveness of the ICS treatment. In girls, an increased BMI can also be a predictor for the risk of developing the late onset BA. 


\section{ABBREVIATIONS}

Bronchial asthma (BA); Body mass index (BMI); Forced expiratory volume in the first second (FEV1); Fat free mass (FFM); Fat mass (FM); Forced vital capacity (FVC); Inhaled corticosteroids (ICS); Percent body fat (PBF); Percent truncal fat (PTF); Total lung capacity (TLC); Total upper arm area (TUA); Upper arm muscle area (UMA)

\section{REFERENCES}

1. Ahmadiafshar A., Tabbekhha S., Mousavinasab N., Khoshnevis P. (2013). Relation between Asthma and Body Mass Index in 6-15 Years Old Children. Acta Med Iran, 51, 615-619.

2. Aldamiz-Echevarría Azuara L., González Pérez-Yarza E., Elorz Lambarri J., Ignacio Ruiz Sanz J., Aquino Fariña L., Zubillaga Huici P. (2001). Effects of inhaled glucocorticoids effects on the body composition in children with moderate asthma. Med Clin (Barc), 116, 12-13.

3. Antonio M.A., Ribeiro J.D., Toro A.A., Piedrabuena A.E., Morcillo A.M. (2003). Evaluation of the Nutritional Status of Children and Adolescents with Asthma. Rev Assoc Med Bras, 49, 367-371.

4. BMI Classification (2006). Global Database on Body Mass Index. World Health Organization.

5. Body Mass Index: BMI for Children and Teens (2010). Center for Disease Control.

6. Brown S., Miller W., Eason J. Exercise physiology: Basis of Human Movement in Health and Disease, Second Edition. Lippincott Williams\&Wilkins, 2006, Philadelphia, PA, $324 \mathrm{p}$.

7. Burgess J., Walters E.H., Byrnes G.B., Giles G.G., Jenkins M.A., Abramson M.J., Hopper J.L., Dharmage S.C. (2007). Childhood adiposity predicts adult-onset current asthma in females: a 25-yr prospective study. Eur Respir J, 29, 668-675.

8. Chen Y.C., Tu Y.K., Huang K.C., Chen P.C., Chu D.C., Lee Y.L. (2014). Pathway From Central Obesity to Childhood Asthma: Physical Fitness and Sedentary Time Are Leading Factors. Am J Respir Crit Care Med, 189, 1194-1203.

9. Davis P., Kercsmar C.M. (2000). Growth in children with chronic lung disease. N Engl J Med, 342, 887-888.

10. De Nijs S.B., Venekamp L.N., Bel E.H. (2013). Adult-onset asthma: is it really different? Eur Respir Rev, 22, 44-52.

11. Del-Rio-Navarro B.E., Castro-Rodriguez J.A., Garibay Nieto N., Berber A., Toussaint G., Sienra-Monge J.J., Romieu I. (2010). Higher metabolic syndrome in obese asthmatic compared to obese nonasthmatic adolescent males. J Asthma, 47, 501-506. 
12. Deurenberg P., Weststrate J.A., Seidell J.C. (1991). Body Mass Index as a Measure of Body Fatness: Age- and sex-specific prediction formula. British Journal of Nutrition, 65, 105-114.

13. Doull I. (2004). The effect of asthma and its treatment on growth. Arch Dis Child, 89, 60-63.

14. El-Sayed Z.A., Hamza R.T., Sayed Nel-D., Mahmoud N.H. (2010). Effect of inhaled corticosteroids on growth and puberty in Egyptian asthmatic children and adolescents. Pak J Biol Sci, 13, 977-984.

15. Fedele D., Janicke D.M., Lim C.S., Abu-Hasan M. (2014). An examination of comorbid asthma and obesity: assessing differences in physical activity, sleep duration, health-related quality of life and parental distress. J Asthma, 51, 275-281.

16. Forno E., Acosta-Pérez E., Brehm J.M., Han Y.Y., Alvarez M., Colón-Semidey A., Canino G., Celedón J.C. (2014). Obesity and adiposity indicators, asthma, and atopy in Puerto Rican children. J Allergy Clin Immunol, 133, 1308-1314.

17. Frisancho A., Tracer D.P. (1987). Standards of Arm Muscle by Stature for the Assessment of Nutritional Status of Children. American Journal of Physical Anthropology 73, 459-465.

18. Fuhlbrigge A., Kelly H.W. (2014). Inhaled corticosteroids in children: effects on bone mineral density and growth. Lancet Respir Med, 2, 487-496.

19. Giannini C., Mohn A., Chiarelli F. (2014). Growth Abnormalities in Children with Type 1 Diabetes, Juvenile Chronic Arthritis, and Asthma. Int J Endocrinol, Feb 4.

20. Gold D.R., Damokosh A.I., Dockery D.W., Berkey C.S. (2003). Body-mass index as a predictor of incident asthma in a prospective cohort of children. Pediatr Pulmonol, 36, 514-521.

21. Guibas G., Manios Y., Xepapadaki P., Moschonis G., Douladiris N., Mavrogianni C., Papadopoulos N.G. (2013). The obesity-asthma link in different ages and the role of body mass index in its investigation: findings from the Genesis and Healthy Growth Studies. Allergy, 68, 1298-1305.

22. Hamid Q., Tulic M. (2008). Immunobiology of Asthma. Annual Review of Physiology, 71, 489-507.

23. Hawlader M.D., Noguchi E., El Arifeen S., Persson L.Å., Moore S.E., Raqib R., Wagatsuma Y. (2013). Nutritional status and childhood wheezing in rural Bangladesh. Public Health Nutr, 17, 1570-1577.

24. Holguin F., Bleecker E.R., Busse W.W., Calhoun W.J., Castro M., Erzurum S.C., Fitzpatrick A.M., Gaston B., Israel E., Jarjour N.N., Moore W.C., Peters S.P., Yonas M., Teague W.G., Wenzel S.E. (2011). Obesity and asthma, an association modified by age of asthma onset. J Allergy Clin Immunol, 127, 1486-1493. 
25. International Study of Asthma and Allergies in Childhood (ISAAC) Steering Committee (1998). Worldwide variations in the prevalence of asthma and allergies in childhood (ISAAC). Eur Respir J, 12, 315-335.

26. Lopes E.A., Fanelli-Galvani A., Prisco C.C., Gonçalves R.C., Jacob C.M., Cabral A.L., Martins M.A., Carvalho C.R. (2007). Assessment of muscle shortening and static posture in children with persistent asthma. Eur J Pediatr, 166, 715-721.

27. Magnusson J.Ö., Kull I., Mai X.M., Wickman M., Bergström A. (2012). Early childhood overweight and asthma and allergic sensitization at 8 years of age. Pediatrics, 129, 70-76.

28. Mahut B., Beydon N., Delclaux C. (2012). Overweight is not a comorbidity factor during childhood asthma: the GrowthOb study. Eur Respir J, 39, 1120-1126.

29. McNarry M.A., Boddy L.M., Stratton G.S. (2013). The relationship between body mass index, aerobic performance and asthma in a pre-pubertal, population-level cohort. Eur J Appl Physiol. 114, 243-249.

30. Mohn A., Verini M., Mele R., De Leonardis C., Chiarelli F. (2004). Adrenal suppression from high-dose inhaled fluticasone propionate in children with asthma. Eur Respir J, 23, 354-355.

31. Musaad S.M., Patterson T., Ericksen M., Lindsey M., Dietrich K., Succop P., Khurana Hershey G.K. (2009). Comparison of anthropometric measures of obesity in childhood allergic asthma: central obesity is most relevant. J Allergy Clin Immunol, 123, 1321-1327.

32. Negri E., Pagano R., Decarli A., La Vecchia C. (1988). Body weight and the prevalence of chronic diseases. J Epidemiol Community Health, 42, 24-29.

33. Nahhas M., Bhopal R., Anandan C., Elton R., Sheikh A. (2014). Investigating the association between obesity and asthma in 6- to 8-year-old Saudi children: a matched case-control study. NPJ Prim Care Respir Med, Jun 5.

34. Porter M., Wegienka G., Havstad S., Nageotte C.G., Johnson C.C., Ownby D.R., Zoratti E.M. (2012). Relationship between childhood body mass index and young adult asthma. Ann Allergy Asthma Immunol, 109, 408-411.

35. Preece M., Law C.M., Davies P.S. (1986). The growth of children with chronic paediatric disease. Clin Endocrinol Metab, 15, 453-477.

36. Priftis K.N., Papadimitriou A., Gatsopoulou E., Yiallouros P.K., Fretzayas A., Nicolaidou P. (2006). The effect of inhaled budesonide on adrenal and growth suppression in asthmatic children. Eur Respir J, 27, 316-320.

37. Raissy H., Blake K. (2013). Does Use of Inhaled Corticosteroid for Management of Asthma in Children Make Them Shorter Adults? Pediatr Allergy Immunol Pulmonol, 26, 99-101.

38. Rasmussen F., Hancox R.J. (2014). Mechanisms of obesity in asthma. Curr Opin Allergy Clin Immunol, 14, 35-43. 
39. Rotteveel J., Potkamp J., Holl H., Delemarre-Van de Waal H.A. (2003). Growth during early childhood in asthmatic children: relation to inhalation steroid dose and clinical severity score. Horm Res, 59, 234-238.

40. Savva S.C., Tornaritis M., Savva M.E., Kourides Y., Panagi A., Silikiotou N., Georgiou C., Kafatos A. (2000). Waist circumference and waist-to-height ratio are better predictors of cardiovascular disease risk factors in children than body mass index. Int J Obes Relat Metab Disord, 24, 1453-1458.

41. Scepanovic A., Petrovic A., Bozic-Krstic V. (2013). Nutritional Status (BMI) in Children Suffering From Asthma. Arch. Biol. Sci, 65, 1157-1162.

42. Sideleva O., Black K., Dixon A.E. (2013). Effects of obesity and weight loss on airway physiology and inflammation in asthma. Pulm Pharmacol Ther, 26, 455-458.

43. Silva Rde C., Assis A.M., Goncalves M.S., Fiaccone R.L., Matos S.M., Barreto M.L., Pinto Ede J., Silva L.A., Rodrigues L.C., Alcantara-Neves N.M. (2013). The prevalence of wheezing and its association with body mass index and abdominal obesity in children. J Asthma, 50, 267-273.

44. Silvestri M., Tosca M., Olcese R., Rossi G.A., Ciprandi G. (2012). Two additional factors in the association between overweight and childhood asthma: inhaled corticosteroids and recurrent respiratory infections. Pediatr Int, 54, 170-171.

45. Sim D., Griffiths A., Armstrong D., Clarke C., Rodda C., Freezer N. (2003). Adrenal suppression from high-dose inhaled fluticasone propionate in children with asthma. Eur Respir J, 21, 633-636.

46. Szroniak A., Labedzka I., Breborowicz A., Niedziela M. (2008). Is body mass index associated with asthma in children? Pneumonol Alergol Pol, 76, 88-95.

47. To T., Vydykhan T.N., Dell S., Tassoudji M., Harris J.K. (2004). Is obesity associated with asthma in young children? J Pediatr, 144, 162-168.

48. Umlawska W., Gąszczyk G., Sands D. (2013). Physical development in children and adolescents with bronchial asthma. Respir Physiol Neurobiol, 187, 108-113.

49. Vangeepuram N., Teitelbaum S.L., Galvez M.P., Brenner B., Doucette J., Wolff M.S. (2011). Measures of obesity associated with asthma diagnosis in ethnic minority children. J Obes, May 10.

50. Vignolo M., Silvestri M., Parodi A., Pistorio A., Battistini E., Rossi G.A., Aicardi G. (2005). Relationship between body mass index and asthma characteristics in a group of Italian children and adolescents. J Asthma, 42, 185-189.

51. Wang R., Custovic A., Simpson A., Belgrave D.C., Lowe L.A., Murray C.S. (2013). Differing associations of BMI and body fat with asthma and lung function in children. Pediatr Pulmonol, Oct 25. 
52. Wang T., Li Y., Ye Y.Y., Huang H., Yi H.L., Chen M., Guo C. (2012). Effects of inhaled corticosteroids on bone age and growth in children with asthma. Zhongguo Dang Dai Er Ke Za Zhi, 14, 359-361.

53. Wells J., Fewtrell M.S. (2006). Measuring Body Composition. Arch Dis Child, 91, 612-617.

54. Willeboordse M., van den Bersselaar D.L., van de Kant K.D., Muris J.W., van Schayck O.C., Dompeling E. (2013). Sex Differences in the Relationship between Asthma and Overweight in Dutch Children: a Survey Study. PLoS One, 8, e77574.

55. Ye Huang Y., Wang Y., Wang D.J. (2013). Association between body mass index and lung function in children with asthma after corticosteroids inhalation. Zhongguo Dang Dai Er Ke Za Zhi, 15, 983-986.

56. Yiallouros P.K., Lamnisos D., Kolokotroni O., Moustaki M., Middleton N. (2013). Associations of body fat percent and body mass index with childhood asthma by age and gender. Obesity (Silver Spring), 21, 474-482.

57. Zeitlin S.R., Bond S., Wootton S., Gregson R.K., Radford M. (1992). Increased resting energy expenditure in childhood asthma: does this contribute towards growth failure? Arch Dis Child, 67, 1366-1369.

\section{Address for correspondence:}

Gundega Lipsberga

Institute of Anatomy and Anthropology, Riga Stradinš̌ University,

Kronvalda blv. 9, Riga, Latvia, LV-1010,

E-mail: gundega.bleidele@gmail.com 